\title{
Antioxidant, alpha-amylase and alpha- glucosidase inhibitory activities of leaf and flower extracts and fractions of Phaulopsis falcisepala C. B. Clarke
}

\author{
Oyindamola 0. Abiodun ${ }^{1 *}$, Rasidat Tijani1 ${ }^{1,2}$, Omonike Ogbole ${ }^{3}$, Edith Ajaiyeoba ${ }^{3}$ \\ 1 University of Ibadan, Ibadan, Nigeria, Department of Pharmacology \& Therapeutics, Ibadan, Nigeria. \\ 2 Moshood Abiola Polytechnic, Ojere, Department of Pharmaceutical Technology, School of Science and Technology, \\ Abeokuta, Nigeria. \\ 3 University of Ibadan, Ibadan, Nigeria, Department of Pharmacognosy, Faculty of Pharmacy, Ibadan, Nigeria.
}

Background: The methanol extracts of leaf and flower of $P$. falcisepala (PFL \& PFF) were evaluated for inhibitors of alpha amylase/glucosidase (AGIs) with antioxidant property.

Methods: The total phenolic (TPC)/flavonoid content (TFC), antioxidant and digestive enzymes inhibitory activities of the PFL, PFF and PFF fractions; n-hexane (PFFHex), ethyl acetate (PFFEA), n-butanol (PFFBUT) and aqueous (PFFAQ) were evaluated.

Results: The PFF had higher TPC, TFC, greater antioxidant and digestive enzymes inhibitory activities than PFL. Thus, PFF fractions were further evaluated. The PFFEA had the highest TPC (161.05 $\pm 6.18 \mathrm{mgGAE} / \mathrm{g}), \mathrm{TFC}(112.54 \pm 1.69 \mathrm{mgQE} / \mathrm{g})$, alpha amylase inhibitory activity $(38.45 \pm 2.50 \mu \mathrm{g} / \mathrm{mL})$ than acarbose $(258.4 \pm 6.37$ $\mu \mathrm{g} / \mathrm{mL} \mathrm{p}<0.05)$. In addition, PFFEA showed higher activities in the Fe2+ reducing antioxidant power and alpha glucosidase inhibitory assays.

Conclusion: The promising activity of the flower of $P$. falcisepala can be further explored in the management of hyperglycaemia and oxidative stress.

Keywords: Alpha amylase, Alpha glucosidase, FRAP, DPPH, Phaulopsis falcisepala

\section{INTRODUCTION}

Diabetes mellitus (DM) is a metabolic disorder of the endocrine system characterized by hyperglycaemia due to defects in insulin secretion, insulin action or both $^{1}$. The disorder impacts significant morbidity and mortality due to associated micro-vascular and macrovascular complications ${ }^{2}$. About 425 million people are living with diabetes worldwide ${ }^{3}$. Hyperglycaemia-induced oxidative and

\footnotetext{
*Corresponding author: Oyindamola 0. Abiodun, e-mail: oyindamolaabiodun1@gmail.com (Received 17 May 2018, accepted 26 June 2018)
} 
nitrosative stress have been singled out as the major links between diabetes and diabetic complications ${ }^{4}$. Hyperglycaemia leads to the generation of free radicals due to autoxidation of glucose and glycosylation of proteins ${ }^{5}$. Oxidative stress can cause endothelial dysfunction, insulin resistance and alterations in number and functions of pancreatic $\beta$-cells. Uncontrolled progression of diabetes and oxidative stress can eventually lead to diabetic microvascular and macrovascular complications $^{6}$. Inhibition of enzymes involved in the metabolism of carbohydrate is one of the therapeutic approaches for reducing post-prandial hyperglycemia7. Inhibitors of amylase and glucosidase (AGIs) delay the breaking down of carbohydrates in the small intestine and diminish the postprandial blood glucose level ${ }^{8}$. Clinically used AGIs include acarbose, emiglitate, miglitol and voglibose, they are used as adjunct to diet and exercise in Type II DM patients in whom glycaemic control is not achieved. Hypoglycaemia is not often observed with AGIs because they do not increase insulin secretion; however, increased delivery of carbohydrate to the colon is commonly observed, which results in increased gas production and gastrointestinal symptoms, such as flatulence and diarrhoea ${ }^{9}$. New AGIs are required to improve the efficacy and safety of this class of drugs. Effort in this study is to search for new AGIs with antioxidant property that can reduce hyperglycaemia-induced oxidative and nitrosative stress through ethnomedicine. Plants have been used since antiquity as source of drugs due to their high efficacy, reduced cost and minimal side effects ${ }^{10}$. Plant contains secondary metabolites that inhibit alpha-amylase which is one of the defence strategies against insect pest ${ }^{11}$. Also, the inhibitors of this enzyme are not readily available in the pharmaceutical industries ${ }^{12}$; this underscores the continuous search for inhibitors from plants. Phaulopsis falcisepala C. B. Clarke (Acanthaceae) is an erect or decumbent herb or shrub found throughout the forest zones from Senegal to Southern Nigeria. It is locally known among the Yorubas as Opa-ogbe and has been used by local indigenous groups for a wide range of medicinal purposes such as treatment of fever, rheumatic pain, diabetes, wounds, parasitic and fungal infection ${ }^{13}$. This study reports the antioxidant, alpha amylase and glucosidase inhibitory activities of Phaulopsis falcisepala.

\section{METHODOLOGY}

\section{Chemicals and reagents}

All reagents were purchased from Sigma Aldrich Co. St Louis, USA. 2, 2-Diphenyl-1- picryl- hydrazyl (DPPH), Aluminium chloride, trichloroacetic acid, Folin-ciocalteu's reagent, catechin, gallic acid, potassium ferricyanide, iron chloride, Acarbose, Starch, maltose, alpha amylase enzyme, alpha glucosidase enzyme, sodium potassium tartarate tetrahydrate, Dinitrosalicylic acid (DNSA), 
Para nitro phenyl hydrazine (PNPG), Sodium bicarbonate distilled water, methanol, buffer salts (Sodium hydroxide, di-sodium hydrogen orthophosphate dehydrate and Sodium dihydrogen orthophosphate).

\section{Plants collection and authentication}

The leaf and flower of P. falcisepala (PFL \& PFF) were collected in Ologun Eru area, Ibadan, Oyo State in September 2013. P. falcisepala was identified and authenticated by Mr. Chuckuma Emmanuel at the Forest Herbarium Ibadan, Forestry Research Institute of Nigeria (FHI 111021), Ibadan where voucher specimen was deposited.

\section{Plant Extraction and Fractionation}

The PFL and PFF (200 g) were air-dried and pulverized. They were extracted in $70 \%$ methanol by maceration at room temperature $\left(29^{\circ} \mathrm{C}\right)$ for 72 hours. The extracts were filtered, and solvent removed using a rotatory evaporator. Percentage yields of the resulting methanol extracts were calculated. The methanol extract of PFF was dissolved in distilled water, partitioned into n-hexane (PFFHex), ethyl acetate (PFFEA), n-butanol (PFFBUT) fractions and the residue from the partitioning was aqueous fraction (PFFAQ). The fractions collected were concentrated with a rotatory evaporator. Percentage yields calculated, and fractions stored at $4^{\circ} \mathrm{C}$ till needed for further study.

\section{In vitro antioxidant assay}

\section{1, 1-Diphenyl-2-picrylhydrazyl (DPPH) free radical scavenging assay}

A modified method of Silva and co-workers was used to determine the scavenging activity of the plant extracts and fractions in DPPH based assay ${ }^{14}$. Briefly, gradient concentrations of the plant extracts and fractions $(6.25-400 \mu \mathrm{g} / \mathrm{mL})$ or standard drug ascorbic acid $(0.25-16 \mu \mathrm{g} / \mathrm{mL})$ were prepared in a 96-well plate. Test plates were incubated for 30 minutes in the dark at room temperature with freshly prepared solution of DPPH $(0.04 \mathrm{mg} / \mathrm{mL})$. Thereafter absorbance was read at $517 \mathrm{~nm}$. Optical density (OD) measured was expressed as the percentage of the control.

\section{$\mathrm{Fe}^{2+}$ reducing antioxidant power potential assay}

The method of Hemalatha et al., 2010 was employed ${ }^{15}$. $1 \mathrm{~mL}$ of varying concentrations of the extracts, fractions and ascorbic acid was added to $2.5 \mathrm{~mL}$ of $0.2 \mathrm{M}$ phosphate buffer ( $\mathrm{pH} 6.6)$ and $2.5 \mathrm{~mL}$ of $1 \%$ potassium ferricyanide. The mixture was incubated at $50^{\circ} \mathrm{C}$ inside the water bath for 20 minutes. Furthermore, $2.5 \mathrm{~mL}$ of $10 \%$ trichloroacetic acid was added and the resulting mixture was centrifuged at $3000 \mathrm{rpm}$ for 10 minutes. To $2.5 \mathrm{~mL}$ of the clear supernatant, $2.5 \mathrm{~mL}$ 
of distilled water and $0.5 \mathrm{~mL}$ of freshly prepared $0.1 \%$ iron chloride was added. The absorbance was read at $700 \mathrm{~nm}$. A blank was prepared without the extract.

\section{Determination of total phenolic content}

The spectrophotometric method of Singleton et al., 1999 was used to determine the total phenolic content of the plant extracts and the fractions ${ }^{16}$. To $0.5 \mathrm{~mL}$ of the extract $(1 \mathrm{mg} / \mathrm{mL}), 2.5 \mathrm{~mL}$ of $10 \%$ Folin-ciocalteu's reagent was added, followed by the addition of $2.5 \mathrm{~mL}$ of $7.5 \%$ sodium bicarbonate. The reaction mixture was then incubated at $45^{\circ} \mathrm{C}$ for 45 minutes and the absorbance was read at $765 \mathrm{~nm}$. The same procedure was repeated for the gradient concentration of quercetin (o.125-1 mg/mL) prepared in methanol which was used to construct the standard curve. The concentration of the phenols in each sample was obtained from the calibrated curve and expressed in terms of quercetin equivalent (mg of QE/g of extract).

\section{Determination of flavonoid concentration}

The Aluminum chloride assay adopted from Quettier et al. (2000) was used in the spectrophotometric determination of the flavonoid present in the plant extracts and fractions ${ }^{17} .1 \mathrm{~mL}$ of $10 \%$ of aluminum chloride was added to $1 \mathrm{~mL}$ of the extract/fractions $(1 \mathrm{mg} / \mathrm{mL})$, the reaction mixture was further incubated at $25^{\circ} \mathrm{C}$ for 60 minutes. The absorbance was then read at $415 \mathrm{~nm}$. The same procedure was repeated for varying concentrations $(0.625-5 \mathrm{mg} / \mathrm{mL}$ ) of gallic acid used to obtain the standard curve. The concentration of the flavonoid was obtained from the calibrated curve and then expressed in terms of gallic acid equivalent (mg of GAE/g of extract).

\section{In vitro digestive enzymes inhibitory activity}

\section{Alpha amylase inhibition assay}

A previously reported method of Tundis et al. (2010) was used to determine the inhibition of alpha amylase activity of the plant extracts and fractions ${ }^{18}$. Seven graded concentrations of the extracts, fractions and acarbose $(31.25-1667 \mu \mathrm{g} /$ $\mathrm{mL}$ ) were obtained through two-fold serial dilution in phosphate buffer $(\mathrm{pH}$ 6.9). One milliter ( $1 \mathrm{~mL}$ ) of the extracts/fractions/acarbose was dispensed into well-labeled test tubes, and $1 \mathrm{~mL}$ of 2 units of $\alpha$ - amylase solution was added. The resulting solution was pre-incubated for $15 \mathrm{~min}$ at $35^{\circ} \mathrm{C}$ and the reaction initiated by the addition of $1 \mathrm{~mL}$ starch solution (1\%). The reaction mixture was further incubated for $5 \mathrm{~min}$ at $35^{\circ} \mathrm{C}$. Finally, $1 \mathrm{~mL}$ of the colour reagent $(96 \mathrm{mM}$ 3, 5-dinitrosalicylic acid and 5.31 M sodium potassium tartrate in 2M sodium hydroxide) was added to terminate the reaction and the tubes incubated inside the water bath at $80^{\circ} \mathrm{C}$ for 15 minutes. The test tubes were removed, cooled on 
ice and the reaction mixture was diluted with $9 \mathrm{~mL}$ of distilled water. Two hundred microliter $(200 \mu \mathrm{L})$ each of the content in the test tubes was transferred into a microtitre plate and the absorbance was read at $540 \mathrm{~nm}$. The amount of maltose formed was extrapolated from a maltose standard curve.

\section{Alpha glucosidase inhibition assay}

A previously reported method was adopted for use ${ }^{19}$. The plant extracts, fractions and acarbose were prepared in phosphate buffer ( $\mathrm{pH}$ 6.9). Seven graded concentrations of the plant extracts/fractions/acarbose $(6.25-800 \mu \mathrm{g} / \mathrm{mL})$ were obtained by two-fold serial dilution in labeled test tubes. One milliter (1mL) of $1 \mathrm{U} /$ $\mathrm{mL}$ of alpha glucosidase enzyme solution was pre-incubated with $500 \mu \mathrm{L}$ of the plant extracts, fractions or acarbose in the test tubes for $10 \mathrm{~min}$ at $35^{\circ} \mathrm{C}$. Thereafter $500 \mu \mathrm{L}$ of $3 \mathrm{mM}$ of para-nitrophenylglucopyranoside (PNPG) was dispensed into the test tubes. The reaction mixture was then incubated for $15 \mathrm{mins}$ at $35^{\circ} \mathrm{C}$. The reaction was terminated by the addition of $2 \mathrm{~mL}$ of $0.1 \mathrm{M}$ sodium bicarbonate. Two hundred microliter $(200 \mu \mathrm{L})$ each of the content in the test tubes was dispensed into a microtitre plate and $\alpha$-glucosidase activity was determined by measuring the amount of the yellow para-nitrophenol released from the PNPG at $405 \mathrm{~nm}$ in Spectramax Gemini XS microplate reader. In the two enzyme assays, control tubes were included in the assay tubes namely; coloured control tubes (contained serially diluted plant extracts/fractions or acarbose alone) and negative control tubes (i. e 100\% enzyme activity, done by replacing plant extracts with buffer). The control tubes were also processed the same way as the test tubes.

\section{Statistical analysis}

All experiments were performed in triplicates and repeated in three independent experiments. Optical density (OD) was expressed as the percentage of the control. Percentage scavenging activity or inhibition of enzyme activity of the plant extracts, fractions or the standard drug in respect to the negative control was calculated. The 50\% inhibitory concentration of plant extracts, fractions, ascorbic acid or acarbose ( $\mathrm{IC}_{50}$ ) was determined using non-linear regression in a commercial Mircocal Origin $®$ statistical package. The $\mathrm{IC}_{50}$ values were means \pm standard error of three independent data. Mann-Whitney $U$ test was used to compare the mean $\mathrm{IC}_{50}$ of the plant extracts/fractions with that of the standard drugs. P-value $<0.05$ was considered significant.

\section{RESULTS}

\section{Yield of Plant Extracts}

The percentage yield of the methanol extracts of the leaf and flower of $P$. falcisepala (PFL and PFF) were 5.5 and $3.8 \%$ respectively (Table 1). Aqueous frac- 
tion of P. falcisepala flower (PFFAQ) had the highest percentage yield of $66.3 \%$ among the fractions (Table 1).

Table 1. Percentage yield, total phenolic and flavonoid content of the methanol extracts and fractions of $P$. falcisepala leaf and flower

\begin{tabular}{|l|c|c|c|}
\hline $\begin{array}{l}\text { Plant extract/ } \\
\text { fractions and drugs }\end{array}$ & $\begin{array}{c}\text { Percentage } \\
\text { Yield (\%) }\end{array}$ & $\begin{array}{c}\text { TPC } \\
\text { (mgGAE/g) }\end{array}$ & $\begin{array}{c}\text { TFC } \\
\text { (mgQE/g) }\end{array}$ \\
\hline $\begin{array}{l}\text { P. falcisepala leaf } \\
\text { (PFL) } \\
\text { MeOH extract }\end{array}$ & 5.5 & $19.53 \pm 0.70$ & $55.55 \pm 0.58$ \\
\hline $\begin{array}{l}\text { P. falcisepala flower } \\
\text { (PFF) } \\
\text { MeOH extract }\end{array}$ & 3.8 & $78.97 \pm 1.13$ & $77.22 \pm 1.06$ \\
\hline $\begin{array}{l}\text { n-Hexane fraction } \\
\text { (PFFHex) }\end{array}$ & 8.6 & $9.51 \pm 2.34$ & $81.55 \pm 0.77$ \\
\hline $\begin{array}{l}\text { Ethyl acetate fraction } \\
\text { (PFFEA) }\end{array}$ & 9.1 & $161.05 \pm 6.18^{*}$ & $112.54 \pm 1.69^{*}$ \\
\hline $\begin{array}{l}\text { n-Butanol fraction } \\
\text { (PFFBUT) }\end{array}$ & 16.0 & $78.29 \pm 3.82$ & $19.42 \pm 0.90$ \\
\hline $\begin{array}{l}\text { Aqueous fraction } \\
\text { (PFFAQ) }\end{array}$ & 66.3 & $20.99 \pm 2.16$ & $9.50 \pm 0.51$ \\
\hline
\end{tabular}

*Ethyl acetate fraction had TPC and TFC significantly higher than other extracts and fractions $(\mathrm{P}<0.05)$.

\section{Determination of Total phenolic and total flavonoid content}

The total phenolic content (TPC) of the plant extracts/fractions expressed as mg of GAE/g of extract was obtained from the calibrated standard curve (equation $\left.\mathrm{y}=0.100 \mathrm{x}+0.013, \mathrm{r}^{2}=0.999\right)$. The TPC of PFL and PFF were 19.53 \pm 0.70 and $78.97 \pm 1.13 \mathrm{mgGAE} / \mathrm{g}$ respectively (Table 1 ). In addition, the TPC in PFF fractions ranged from $9.51 \pm 2.34$ to $161.05 \pm 6.18 \mathrm{mgGAE} / \mathrm{g}$. The PFF fractions; PFFEA followed by PFFBUT had the highest TPC (Table 1). The total flavonoid content (TFC) values were expressed as $\mathrm{mg}$ of $\mathrm{QE} / \mathrm{g}$ of the extracts/fractions as obtained from the standard curve with equation $\mathrm{y}=0.685 \mathrm{x}-0.082, \mathrm{r}^{2}=0.988$. The TFC of PFL and PFF were 55.55 \pm 0.58 and $77.22 \pm 1.06 \mathrm{mgQE} / \mathrm{g}$ respectively (Table1). In addition, the TFC of PFF fractions ranged from $9.50 \pm 0.51$ to $112.54 \pm 1.69 \mathrm{mgGAE} / \mathrm{g}$. The fraction of PFF; PFFEA followed by PFFHex had the highest TFC (Table 1).

\section{In vitro antioxidant activity of the methanol extracts and fractions of $P$. falcisepala leaf and flower}

The IC50 of PFL and PFF in DPPH free radical scavenging activity are presented in Table 2. The PFL is inactive with $\mathrm{IC}_{50}>400 \mu \mathrm{g} / \mathrm{mL}$ while PFF had $\mathrm{IC}_{50}$ of 
$28.76 \pm 0.73 \mu \mathrm{g} / \mathrm{mL}$ (Table 2). The active PFF was dissolved in distilled water and partitioned into n-hexane, ethyl acetate and n-butanol yielding 4 fractions namely; PFFHex, PFFEA, PFFBUT and PFFAQ. Of the 4 fractions evaluated PFFAQ showed the highest antioxidant activity, followed by PFFHex with $\mathrm{IC}_{50}$ of $13.81 \pm 0.77 \mu \mathrm{g} / \mathrm{mL}$ and $35.56 \pm 1.34 \mu \mathrm{g} / \mathrm{mL}$ respectively (Table 2). Ascorbic acid the standard drug had $\mathrm{IC}_{50}$ of $7.87 \pm 0.40 \mu \mathrm{g} / \mathrm{mL}$. In the $\mathrm{Fe}^{2+}$ reducing antioxidant power, increase in absorbance value as the concentration increases shows increase in the reducing power of the extracts/ascorbic acid. Methanol extract of $P$. falcisepala flower is more active than its methanol leaf extract (Fig. 1). In addition, the order of antioxidant activity of PFF fractions is PFFEA $>$ PFFBUT $>$ PFFAQ $>$ PFFHex (Fig. 1). At the highest concentration tested (277.77 $\mu \mathrm{g} / \mathrm{mL})$, the absorbance of PFF fractions ranged from $0.37-0.92 \mathrm{~nm}$. The ascorbic acid had the highest absorbance $(1.57 \mathrm{~nm}$ ) followed by PFFEA and PFFBUT (0.89 \& $0.92 \mathrm{~nm}$ ).

Table 2. Alpha amylase and glucosidase inhibitory and DPPH scavenging activities of the methanol extracts and fractions of $P$. falcisepala leaf and flower

\begin{tabular}{|c|c|c|c|}
\hline \multirow{2}{*}{$\begin{array}{l}\text { Plant extracts/ } \\
\text { fractions and } \\
\text { standard drug }\end{array}$} & \multicolumn{3}{|c|}{$50 \%$ Inhibitory Concentration $\left(\mathrm{IC}_{50}\right) \mu \mathrm{g} / \mathrm{mL}$} \\
\hline & Alpha amylase & Alpha glucosidase & $\begin{array}{c}\text { DPPH Scavenging } \\
\text { activity }\end{array}$ \\
\hline $\begin{array}{l}\text { P. falcisepala leaf } \\
\text { (PFL) MeOH extract }\end{array}$ & $880.0 \pm 0.25$ & $133.1 \pm 3.24$ & $>400$ \\
\hline $\begin{array}{l}\text { P. falcisepala flower } \\
\text { (PFF) MeOH extract }\end{array}$ & $462.4 \pm 2.53$ & $86.05 \pm 2.41$ & $28.76 \pm 0.73$ \\
\hline $\begin{array}{l}\text { n-Hexane fraction } \\
\text { (PFFHex) }\end{array}$ & $39.93 \pm 3.28^{*}$ & $228.70 \pm 1.70$ & $35.56 \pm 1.34$ \\
\hline $\begin{array}{l}\text { Ethyl acetate fraction } \\
\text { (PFFEA) }\end{array}$ & $38.45 \pm 2.50^{\star}$ & $52.99 \pm 1.07^{* *}$ & $83.77 \pm 5.31$ \\
\hline $\begin{array}{l}\text { n-Butanol fraction } \\
\text { (PFFBUT) }\end{array}$ & $69.92 \pm 8.60^{*}$ & $291.60 \pm 1.77$ & $180.10 \pm 1.51$ \\
\hline $\begin{array}{l}\text { Aqueous fraction } \\
\text { (PFFAQ) }\end{array}$ & $38.65 \pm 2.13^{*}$ & $154.90 \pm 1.63$ & $13.81 \pm 0.77$ \\
\hline Acarbose & $258.40 \pm 6.37$ & $48.50 \pm 1.30 * *$ & \\
\hline Ascorbic Acid & & & $7.87 \pm 0.40$ \\
\hline
\end{tabular}

${ }^{*}$ All PFF fractions significantly active than acarbose $(\mathrm{P}<0.0001),{ }^{* *}$ Both results were Comparable $(\mathrm{P}>0.06)$. 


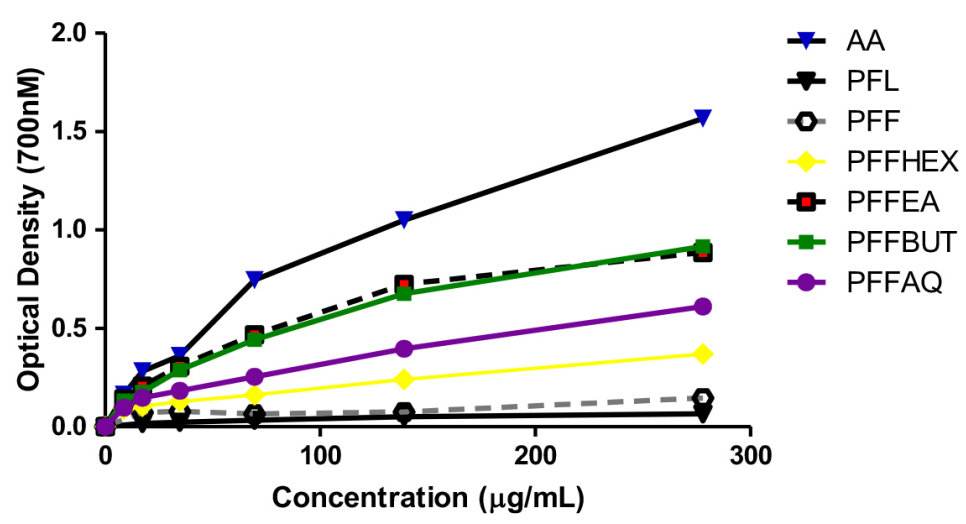

AA - ascorbic acid, PFL - methanol extract of P. falcisepalaleaf, PFF -methanol extract of $P$. falcisepala flower, PFFHEX - hexane fraction of P. falcisepala flower, PFFEA- ethyl acetate fraction of P. falcisepala flower, PFFBUT- buthanol fraction of P. falcisepala flower, PFFAQ-Aqueous fraction of P. falcisepala flower.

Figure 1. $\mathrm{Fe}^{2+}$ reducing antioxidant power potential of methanol extracts and fractions of $P$. falcisepala leaf and flower

\section{In-vitro alpha amylase and glucosidase inhibitory activity of methanol extracts and fractions of $P$. falcisepala leaf and flower}

The PFF produced a higher inhibitory activity against alpha amylase with $\mathrm{IC}_{50}$ of $462.40 \pm 2.53 \mu \mathrm{g} / \mathrm{mL}$ while PFL had $\mathrm{IC}_{50}$ of $880.0 \pm 0.25 \mu \mathrm{g} / \mathrm{mL}$ (Table 2). All the PFF fractions had greater activity $(38.45 \pm 2.50-69.92 \pm 8.6 \mu \mathrm{g} / \mathrm{mL})$ than acarbose $(258.40 \pm 6.37 \mu \mathrm{g} / \mathrm{mL})$. Furthermore, in the alpha glucosidase inhibitory assay, PFF had higher inhibitory activity with $\mathrm{IC}_{50}$ of $86.05 \pm 2.41 \mu \mathrm{g} /$ $\mathrm{mL}$ than PFL ( $\mathrm{IC}_{50}$ of $133.1 \pm 3.24 \mu \mathrm{g} / \mathrm{mL}$, Table 2). In addition, the PFFEA was the most active with $\mathrm{IC}_{50}$ of $52.99 \pm 1.07 \mu \mathrm{g} / \mathrm{mL}$ (Table 2). The $\mathrm{IC}_{50}$ value of the standard drug acarbose was $48.50 \pm 1.30 \mu \mathrm{g} / \mathrm{mL}$.

\section{DISCUSSION}

Diabetes is a metabolic disease that is associated with chronic hyperglycemia as a result of disturbance in carbohydrate, fat and protein metabolism due to defects in insulin secretion and action ${ }^{1}$. Uncontrolled hyperglycemia can cause excessive generation of intracellular reactive oxygen species (ROS), thus leading to oxidation of important macromolecules including proteins, lipids, carbohydrate and $\mathrm{DNA}^{5}$. Inhibition of enzymes involved in the metabolism of carbohydrate is one of the therapeutic approaches for reducing post-prandial hyperglycemia ${ }^{8}$. Thus, the approach in this study is to evaluate Phaulopsis falcisepala for inhibitors of $\alpha$-amylase and $\alpha$-glucosidase with antioxidant activity. 
This is because plants have been shown to produce a large variety of amylase inhibitors that offer protection against insects, their larvae, and microbial pathogens $^{11}$. Previous antioxidant report showed that $P$. fascisepala leaf extract had less scavenging effect on DPPH radical and reducing power on $\mathrm{Fe}^{3+}$ ferricyanide complex but better $\mathrm{Fe}^{2+-}$ chelating ability ${ }^{20}$. However, in this study we evaluated both the leaf and flower of $P$. fascisepala. The flower of methanol extract of $P$. falcisepala (PFF) was 13 times more active than its leaf extract in the DPPH radical scavenging assay. The PFF had higher phenols and flavonoids content than its leaf extract. The higher antioxidant activity observed in the PFF compared to PFL extract could be due to the abundant presence of major secondary metabolites such as phenols and flavonoids. Several studies have reported that polyphenols, such as flavonoids, hydroxycinnamic acids and proanthocyanidins, act as powerful antioxidants ${ }^{21-23}$. The capacity of flavonoids to act as antioxidants depends upon their molecular structure. The position of hydroxyl groups and other features in the chemical structure of flavonoids are important for their antioxidant and free radical scavenging activities ${ }^{24}$. Phenolic antioxidants have been recognized as an important class of food ingredients and are currently added to various food products in order to provide additional health benefits ${ }^{23}{ }^{25}$. Furthermore, in the Ferric ions $\left(\mathrm{Fe}^{3+}\right)$ reducing antioxidant power assay (FRAP), increase in absorbance as the concentration increases is an indication of a strong reducing potential. Ethyl acetate (PFFEA) and butanol (PFFBUT) fractions of PFF showed stronger reducing potential than the other fractions and extracts. In the $\alpha$-amylase and $\alpha$-glucosidase inhibitory assays, PFF was more active in the two assays than PFL. Fractionation of PFF resulted in four fractions that were significantly more active than its crude extract in alpha amylase inhibitory assays. All the four fractions of PFF showed higher a-amylase inhibitory activity than acarbose $(\mathrm{p}<0.001)$. It appears its alpha amylase inhibitory activity is distributed in the four fractions unlike the DPPH and alpha glucosidase inhibitory activities that appear to be concentrated in the aqueous and ethyl acetate fractions, respectively. There are limited pharmacological studies on this plant. The alpha amylase and alpha glucosidase inhibitory activities of the flower of $P$. falcisepala appeared to be reported in this study for the first time.

\section{CONCLUSION}

The flower of Phaulopsis falcisepala showed higher antioxidant, alpha amylase and glucosidase inhibitory activities than its leaf. The activity observed might be due to higher phenolic and flavonoid contents in the flower than the leaf. The flower of $P$. falcisepala can serve as potential sources of natural agents that can be further explored to control post prandial hyperglycemia and associated oxidative stress. 


\section{CONFLICT OF INTERESTS}

The authors declare no conflict of interest.

\section{REFERENCES}

1. American Diabetes Association. Diagnosis and Classification of Diabetes Mellitus. Diabetes Care. 2009, 32(Suppl 1), S62-S67. doi: 10.2337/dco9-So62.

2. Orasanu, G.; Plutzky, J. The pathologic continuum of diabetic vascular disease. J Am Coll Cardiol. 2009, 53(5 Suppl), S35-42.

3. International Diabetes Federation, IDF diabetes atlas, $8^{\text {th }}$ edition. Brussels, Belgium: International Diabetes Federation, 2017.

4. Negi, G.; Kumar, A.; Joshi R. P.; Sharma, S. S. Oxidative stress and Nrf2 in the pathophysiology of diabetic neuropathy: old perspective with a new angle. Biochem Biophys Res Commun. 2011, 408(1), 1-5.

5. Matough, F. A.; Budin, S. B.; Hamid, Z. A.; Alwahaibi, N.; Mohamed, J. The Role of Oxidative Stress and Antioxidants in Diabetic Complications. Sultan Qaboos Univ Med J. 2012, 12(1), $5^{-18 .}$

6. Bandeira, S. D.; Da Fonseca, G. S; Guedes, L. A.; Rabelo, M. O.; Goulart, D. T.; Vasconcelos, E. T. Oxidative stress as well an underlying contributor in the development of chronic complications in diabetes mellitus. Int. J. Mol. Sci. 2013, 14(2), 3265-84.

7. Rhabasa-Lhoret, R.; Chiasson J. L. Alpha glucosidase inhibitors. An international textbook of Diabetes mellitus. 3rd ed. John Wiley \& Sons Ltd. 2004, 901-914.

8. Kumar, D.; Analava, B. M.; Manjunatha, M. A comparative study of alpha amylase inhibitory activities of common antidiabetic plants of Kharagpur 1 block. Int. J. Green Pharm. 2010, 4, $115^{-121 .}$

9. Derosa, G.; Maffioli, P. $\alpha$-Glucosidase inhibitors and their use in clinical practice. Arch Med Sci. 2012, 8, 899-906.

10. Gauresh, S.; Rahul, C.; Jayant, S.; Sadhana, S. Inhibition of carbohydrate hydrolysing enzymes by methanolic extract of Couroupita guianensis leaves. Int. J. Pharm. Biosci. 2012 , $3,511-520$.

11. Mehrabadi, M.; Bandani, A. R. Purification and characterization of midgut $\alpha$-amylase of Eurygaster integriceps. J. Entomol. Sci. 2011, 12, 25-32.

12. Mehrabadi, M.; Bandani, A. R.; Kwon, O. Biochemical characterization of digestive $\alpha$-dglucosidase and $\beta$-d-glucosidase from labial glands and midgut of wheat bug Eurygaster maura. Entomol. Res. 2011, 41(3),81-87.

13. Burkill, H. M. The useful plants of West Tropical Africa. Royal Botanical Garden, Kews. 1985, 388-9.

14. Silva, E. M.; Sonza, J.; Rogez, H.; Rees, J. F; Larondelle, Y. Antioxidant activity and polyphenolic contents of fifteen selected plant species from the Amazonian region. Food Chem. 2oo6, 101, 1012-1018.

15. Hemalatha, S.; Lalitha, P.; Arulpriya, P. Antioxidant activities of the extracts of the aerial roots of Pothos aurea (Linden ex Andre). Der Pharma Chemica. 2010, 2(6), 84-89

16. Singleton, V. L.; Orthofer, R.; Lamuela-Raventos, R. M. Analysis of total phenols and other oxidation substrates and antioxidants by means of Folin-Ciocalteu reagent. Methods Enzymol. 1999, 299, 152-178. 
17. Quettier, D. C.; Gressier, B.; Vasseur, J.; Dine, T.; Brunet, C.; Luyckx, M. C.; Cayin, J.C.; Bailleul, F.; Trotin, F. Phenolic compounds and antioxidant activities of buckwheat (Fagopyrum esculentum Moench) hulls and flour. J. Ethnopharmacol. 20oo, 72, 35-42.

18. Tundis, R.; Loizzo, M. R.; Menichini, F. Natural products as alpha-amylase and alpha-glucosidase inhibitors and their hypoglycemic potential in the treatment of diabetes. Mini. Rev. Med. Chem. 2010, 10(4), 315-331.

19. Kazeem, M. I.; Adamson, J. O.; Ogunwande, I. A. Modes of inhibition of alpha amylase and alpha glucosidase by aqueous extract of Morinda lucida Benth leaf. BioMed. Res. Int. article. 2013, ID 527570, 6 pages.

20. Adesegun, S.A.; Fajana, A.; Orabueze, C. I.; Coker, H. A. Evaluation of antioxidant properties of Phaulopsis fascisepala C.B.Cl. (Acanthaceae). Evid. Based. Complement. Alternat Med. 2007, 6(2), 227-231

21. Saurai, P.; Silymarin, R. As a natural antioxidant: An overview of the current evidence and perspectives. Antioxidants. 2015, 4, 204-247.

22. Lopez-Alarcon, C.; Denicola, A. Evaluating the antioxidant capacity of natural products: A review on chemical and cellular-based assays. Anal.Chim. Acta. 2013, 763, 1-10

23. Martin-Sanchez, A.; Cherif, S.; Ben-Abda, J.; Barber-Valles, X. Phytochemicals in date coproducts and their antioxidant activity. Food Chem. 2014, 158, 513-520.

24. Tapas, A. R.; Sakarkar, D. M.; Kakde, R. B. Flavonoids as Nutraceuticals: A Review. Tropical Journal of Pharmaceutical Research. 2008, 7, 1089-1099.

25. Stevanovic, T.; Diouf, N.; Garcia-Perez, M. Bioactive polyphenols from healthy diets and forest biomass. Curr. Nutr. Food Science. 2009, 5, 264-295. 